\title{
A Rare Case of Thecoma In a Dog
}

\author{
C Iaria ${ }^{1}$, JM Abbate ${ }^{2}$, G De Benedetto ${ }^{2}$, S Mazzullo ${ }^{3}$, A Ieni ${ }^{4}$, A La pietra ${ }^{3}$, G Mazzullo² and \\ G Lanteri ${ }^{2 *}$
}

${ }^{1}$ Department of Chemical, Biological, Pharmaceutical and Environmental Sciences, University of Messina, Italia

${ }^{2}$ Department of Veterinary Sciences, University of Messina, Italia

${ }^{3}$ Veterinary practitioner

${ }^{4}$ Department of Human Pathology of Adult and Evolutive Age, Section of Pathology, University of Messina, Italia

*Corresponding author: G Lanteri, Department of Veterinary Sciences, University of Messina, Italia

\section{ARTICLE INFO}

Received: 慧 June 21, 2019

Published: 㓞 June 28, 2019

Citation: C Iaria, JM Abbate, G De Benedetto, S Mazzullo, G Lanteri, et al., A Rare Case of Thecoma In a Dog. Biomed J Sci \& Tech Res 19(2)-2019. BJSTR. MS.ID.003270.

Keywords: Diagnosis; Dog; Immunohistochemistry; Tumour

\begin{abstract}
Thecoma is an ovarian tumour which has rarely been described in dog and must be differentiated from other similar neoplasm such as granulosa cell tumour, clear cell carcinoma, luteoma, fibroma, above all by histopathological examination. Aim of the paper is to report the histochemical and immunohistochemical findings useful to identify this tumour rarely found in dog. Tumour tissue was negative for cytokeratin and HBME-1, whereas strong immunopositivity with vimentin, calretinin and inhibin was seen; Gomori histochemical stain highlighted an abundant reticulin network among neoplastic cells. Negativity to cytokeratin and HBME-1 excluded the differential diagnosis of fibroma, while positivity to vimentin, calretinin and inhibin supported the differential diagnosis of granulosa cell tumour. The absence of spindle cells and strong presence of reticulin among tumour cells confirmed the final diagnosis of thecoma.
\end{abstract}

\section{Introduction}

Ovarian tumours represent a rare neoplastic condition in dogs and is generally observed in older subjects; they are classified based on the tissue involved; epithelial, stromal and germinal [1]. Among them, sex cord-stromal tumours are generally represented by granulosa cell tumours and rarely thecomas or interstitial cell tumours [2]. Granulosa cell tumours are generally hormone-active neoplasms showing variable macroscopic features, often very large, smooth and grey-yellowish in colour. On a cut surface, differently sized cysts with variable wall thickness and haemorrhages may be observed. Histologically, granulosa cell tumours are made up of clusters of granulosa mature cells, separated by connective septa.

Thecomas are characterized by large masses with a lardaceous aspect and fibrous consistence, deriving from the follicular theca, mainly the internal one. Thecomas have a very low incidence and are usually benign with an expansive growth. Macroscopically, they are characterized by a white-yellowish or orange voluminous fibrous mass, with the presence of necrotic or haemorrhagic foci. Histologically, thecomas are characterized by pale, densely packed, cells with a variable amount of fibrocytes and fibroblasts, among which some sparse follicles may be seen [2]. Tumours consist of oval or spindle-shaped cells, irregularly arranged in clumps separated by fibrous septa or interlacing bundles, which are not encapsulated. Individual cells have round or elongated nuclei, and the cytoplasm may contain lipid vacuoles, which are indicative of steroid hormone production $[3,4]$.

Thecomas in bitches are rarely reported and the distinction between thecoma and other mesenchymal tumours such as leiomyoma and fibroma can be difficult [5]. To distinguish this tumour from its related forms, it is necessary to use histochemical and immunohistochemical techniques [6-9]. The aim of the present paper is to show a rare case of thecoma in dog describing the histochemical and immunohistochemical patterns useful for its diagnosis.

\section{Materials and Methods}

A clinical investigation was carried out. A 5-year-old female Yorkshire was presented at a private veterinary ambulatory 
because of a severe abdomen enlargement. Long term medical history referred the bitch has not been coupled, had regular heats, and lived in house as the only domestic animal. Macroscopic and Physical Examination were carried out and after premedication, induction and anaesthesia, an ovary-hysterectomy was carried out. After removal from the abdomen the mass was photographed and measured. The pathological ovary was sent to the Unit of Veterinary Pathology, University of Messina for histological, histochemical and immunohistochemical exams.

The US investigation was performed on the lumbar tract as well as the topographic area of kidney with the dog positioned in lateral recumbence, using a portable Esaote Mylab 5 Vet echograph with a 5.0 MHz convex probe. For histological examinations, the mass was fixed in $10 \%$ formalin solution for 48 hours, completely sampled, routinely processed and paraffin-embedded at $56^{\circ} \mathrm{C} .4$-micron thick sections were cut and routinely stained with haematoxylin and eosin, a parallel section was used for histochemical procedure to detect reticulin fibres with Gomori silver impregnation (staining kit, Bio-Optica, Milan, Italy) and Sudan Black (staining kit, Bio-Optica, Milan, Italy). Immunohistochemical examinations were performed on 10-micron thick sections, using commercially obtained antibodies against: broad spectrum cytokeratins (CK) AE1/AE3 (DakoCytomation, Copenhagen, Denmark; working dilution 1:300), vimentin (DakoCytomation, Copenhagen, Denmark; w.d.1:1000), Epithelial membrane antigen (EMA) (DakoCytomation, Copenhagen, Denmark; working dilution 1:1000), CK 7 (DakoCytomation, Copenhagen, Denmark; working dilution 1:100), Calretinin
(DakoCytomation, Copenhagen, Denmark; working dilution 1:100), estrogen receptor (DakoCytomation, Copenhagen, Denmark; working dilution 1:100), HBME-1 (DakoCytomation, Copenhagen, Denmark; working dilution 1:100), Ki 67 (DakoCytomation, Copenhagen, Denmark; working dilution 1:150) [10-15].

\section{Results}

Macroscopic and Physical Examination of the dog also revealed slight depression, $4.1 \mathrm{~kg}$ in weight, body condition score (bcs) 3/5, normal mucosae, normal lymph nodes, temperature 38.2, 90 beats per minute, 66 breaths per minute, major organ functions in the standard. At abdominal palpation, a firm ovoid mass was detected and ultrasonography (US), thoracic radiology and haemato biochemistry were then performed and were in the standards for a 5-year-old dog (data not provided). US examination showed an ovarian mass of about $10 \mathrm{~cm}$ in longitudinal diameter and $\mathrm{cm}$ 5.5 in transverse (Figure 1). The mass had distinct margins and parenchyma of the medulla was rich in an echogenic, ovoid, cystic areas, parenchyma of cortex was dis-homogeneous, varying from hyperechogenic to hypoechogenic. From the US exam, a suspicious diagnosis of ovarian neoplasia was made and thus prompt surgical intervention was planned. Ovary-hysterectomy showed a $10 \mathrm{~cm}$ in medium size, irregularly round, red brownish in colour, firm in consistence mass (Figure 2). On the cut surface, in the cortical region, there were several haemorrhagic, necrotic areas, with the presence, in the medullary region, of different cystic structures with serous content, varying in size from a few millimetres to 1.5 $\mathrm{cm}$ in diameter

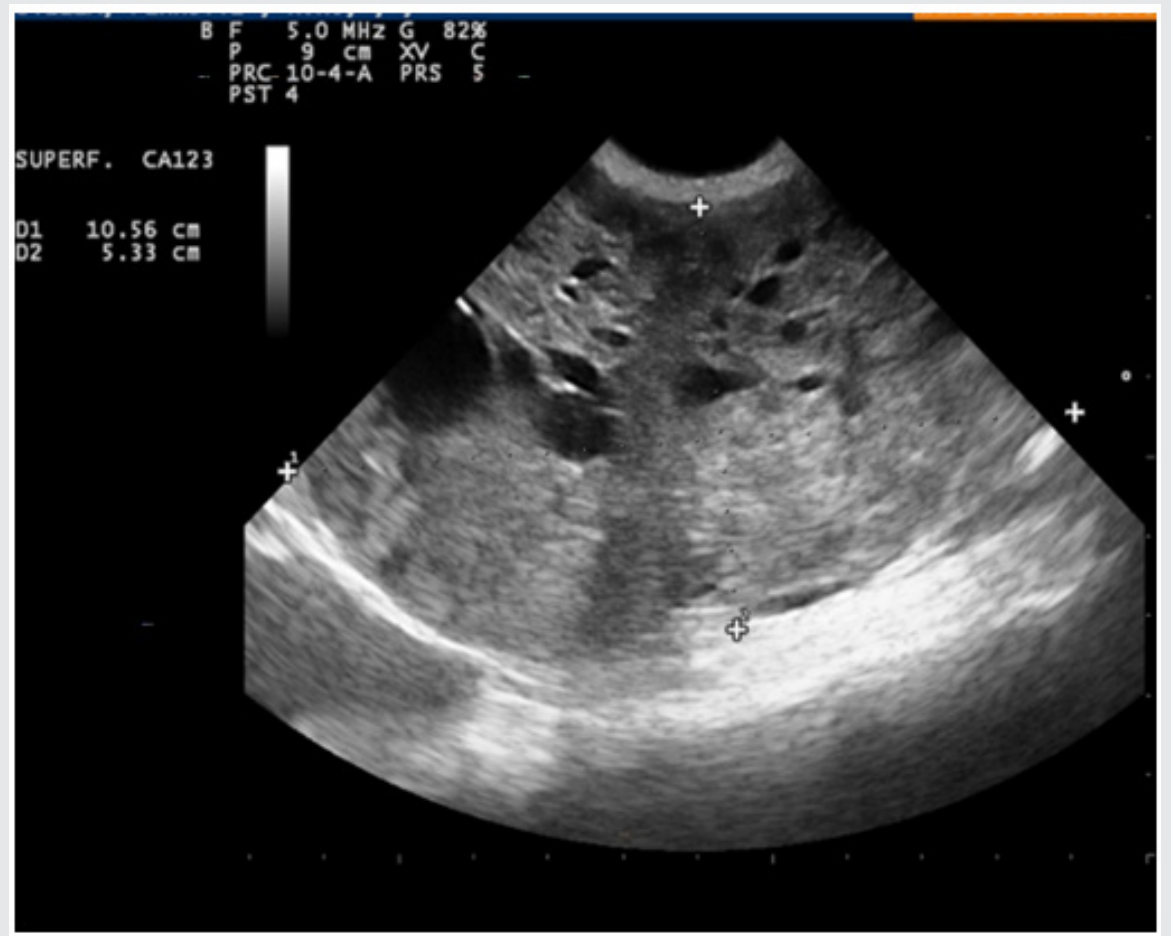

Figure 1: Ultrasonography showing an ovarian mass with distinct margins and parenchyma of the medulla rich in an echogenic, ovoid, cystic areas. 


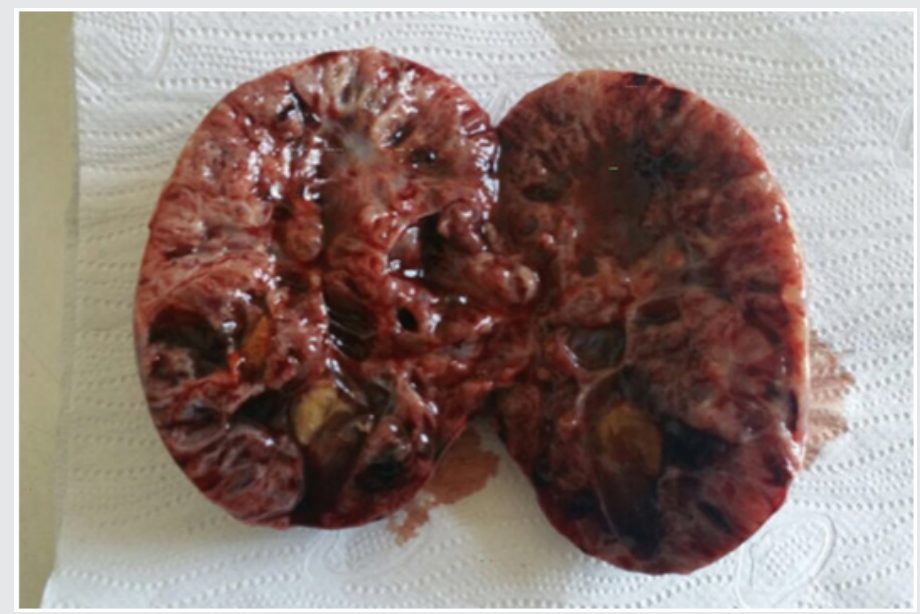

Figure 2: Macroscopic evidence of the mass with several haemorrhagic, necrotic areas in the cortical region and presence of differently sized cysts in the medullary region.

At histopathological evaluation, both round and polygonal cells, with cytoplasm rich in lipid droplets (Figure 3) giving the neoplastic tissue a foaming feature, were seen. Cellular limits were difficult to see and nuclei were ovoid in shape. Tumour cells were arranged in nests (Figure 4). Gomori reticulin staining demonstrated an abundant reticulin network around each singular tumour element (Figure 5). At immunohistochemical examinations, tumour tissue was negative for cytokeratins, strongly positive when checked with vimentin (Figure 6), positive for inhibin (Figure 7) and calretinin, whilst was negative for HBME-1.

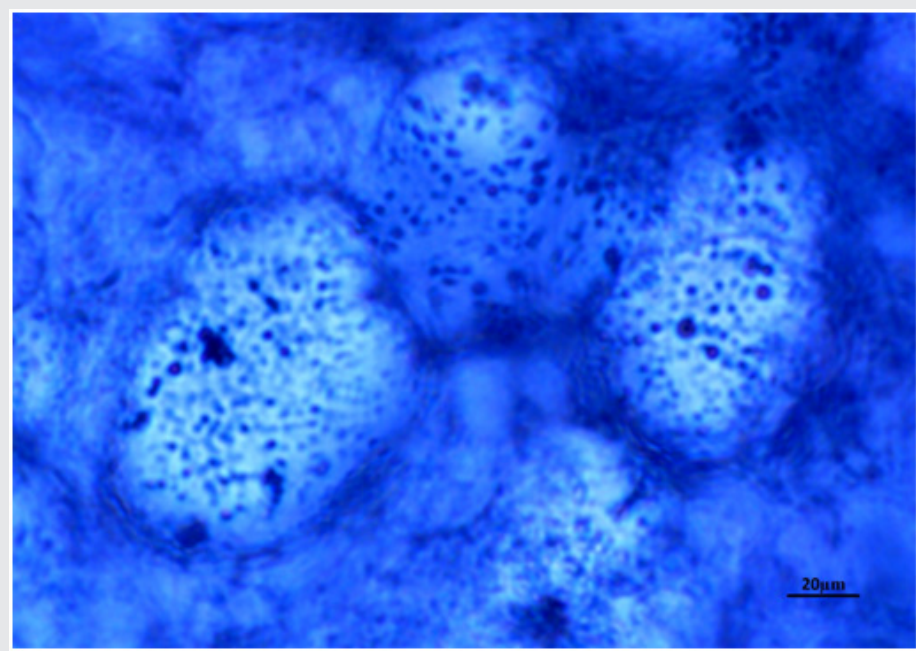

Figure 3: Sudan Black stained histological section showing lipid droplets in cytoplasm (40x).

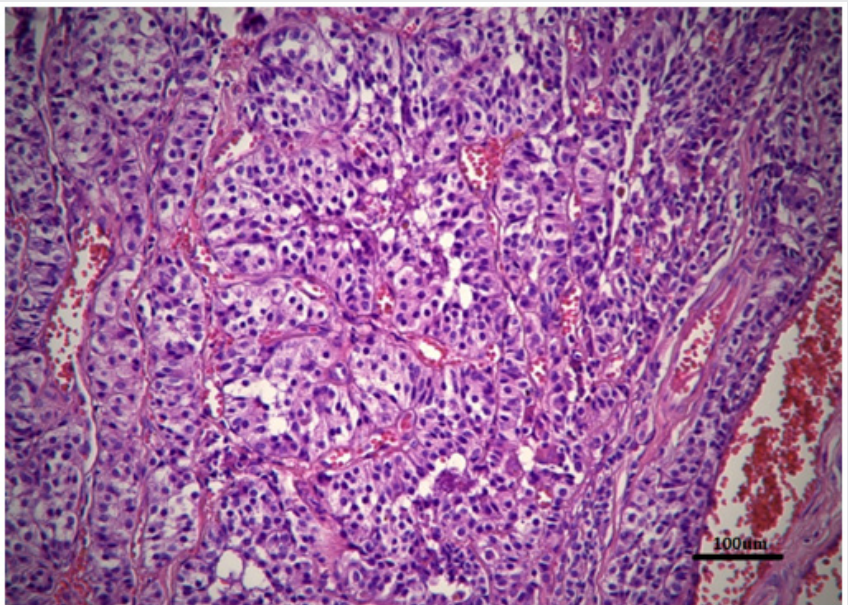

Figure 4: H\&E stained histological section showing round and polygonal cells arranged in nests with cytoplasm rich in lipid droplets (20x). 


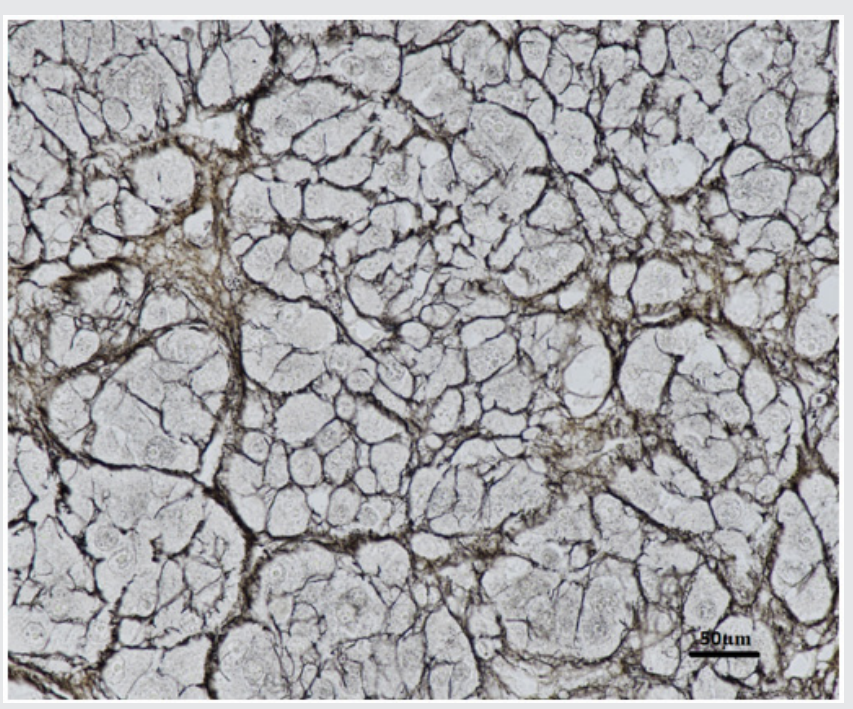

Figure 5: Gomori stain confirming abundant reticulin network around tumour cells (20x).

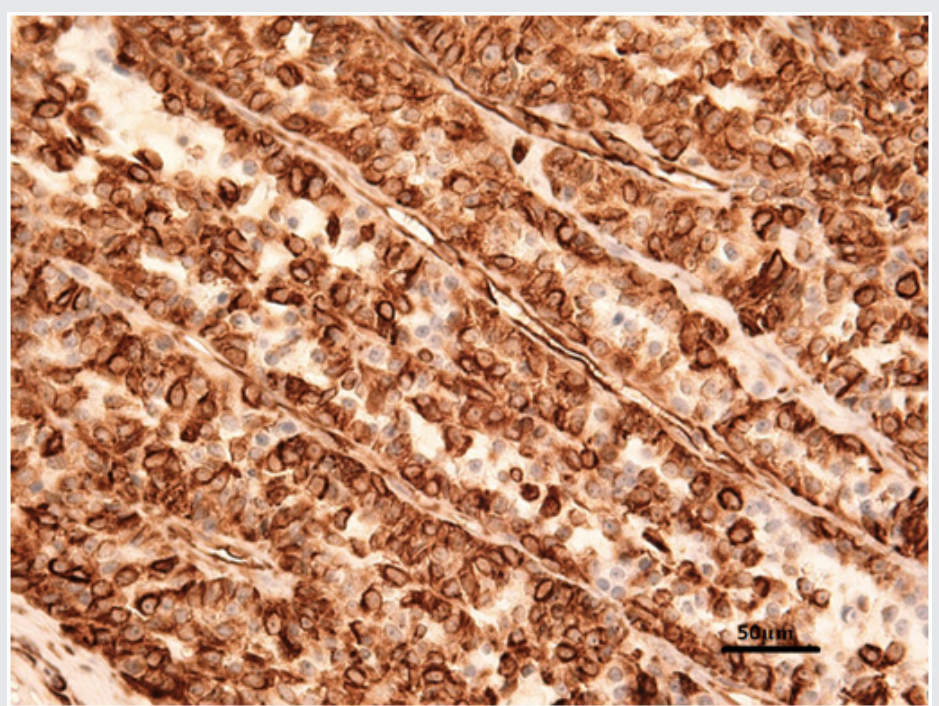

Figure 6: Strong positive immunohistochemical reaction for Vimentin (40x).

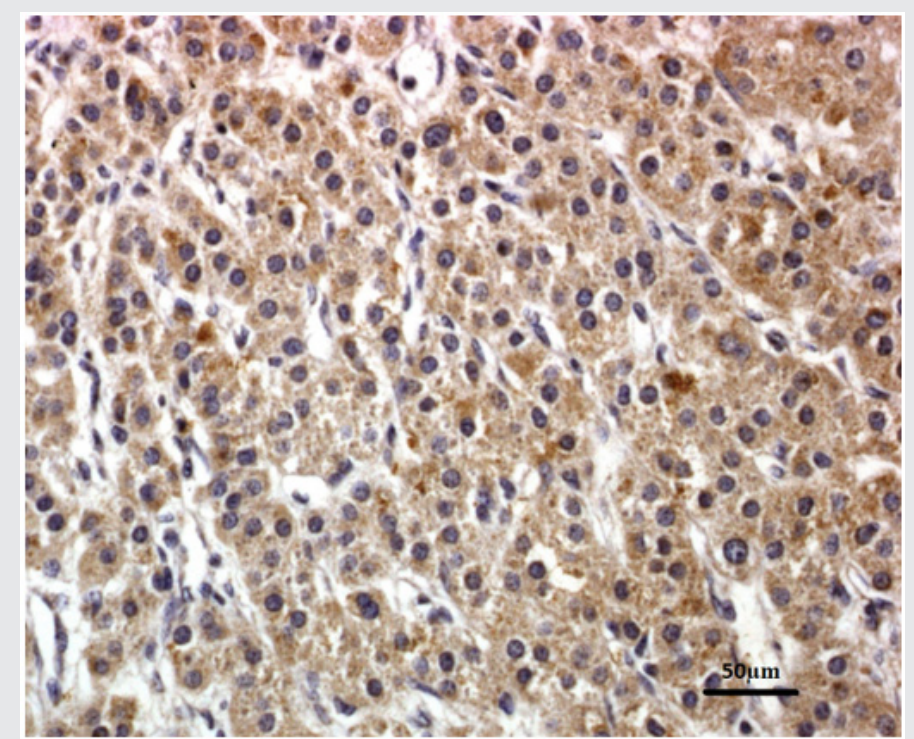

Figure 7: Strong positive immunohistochemical staining for Inhibin (40x). 


\section{Discussion and Conclusion}

From the results obtained, ultrasonography is a basic tool in investigations regarding abdominal swelling as it permits to localize tissue change, its entity, and the involvement of surrounding areas in a very short time, and thus permits quick decisions on how to proceed in successive phases. Precision in measurement must be underlined, considering it was totally superimposable to what was later obtained after organ extraction. Aid provided by US permits intervention in a precise and aware manner, both clinically and surgically, and avoids the necessity of going in blind as in the past. Today, US, with the aid of measurement tools, as well as with the possibility of using the Doppler test, means performing a surgical operation in as safe a way as possible. Nevertheless, data provided also permit to select the best anaesthetic protocols, as well as the best surgical technique for each of the various possible situations in veterinary medicine.

From the histopathological exam, granulosa cell tumour, clear cell carcinoma and fibroma must be considered in differential diagnosis. The origin of the tumour was definitively demonstrated by using histochemistry and immunohistochemistry. As expected for sex cord tumours, the antibody anti-vimentin and calretinin were strongly and diffusively expressed in all tumour cells. CKAE1 and CKAE3, as well as CK7, were negative, in accordance with Akihara et al. [7]. Inhibin was slightly (as compared to vimentin expression) positive in most of the cells, described as a possible feature in dog, in histological nest type. HBME-1 immunoreaction was negative excluding the differential diagnosis of fibroma, in agreement with Banco [6]. Finally, the lack of spindle cells and the abundant reticulin highlighted by Gomori staining were consistent with a diagnosis of thecoma.

\section{References}

1. Nelson RW, Couto CG (2011) Medicina Interna Del Cane e Del Gatto $4^{\text {th }}$ (edn.). Elsevier srl

\section{ISSN: 2574-1241}

DOI: 10.26717/BJSTR.2019.19.003270

G Lanteri. Biomed J Sci \& Tech Res

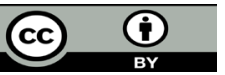

This work is licensed under Creative Commons Attribution 4.0 License

Submission Link: https://biomedres.us/submit-manuscript.php
2. Kennedy PC, Cullen JM, Edwards JF (1998) Histological Classification of Tumors of the Genital System of Domestic Animals. Armed Forces Institute of Pathology $2^{\text {nd }}(e d n$.$) p. 4$.

3. Tilley C, Christopher DM Fletcher (2015) Diagnostic Histopathology of Tumors, $4^{\text {th }}$ (edn.). Elsevier Saunders, Philadelphia.

4. Meuten DJ (2016) Tumors in Domestic Animals $5^{\text {th }}$ (edn.). John Wiley \& Sons.

5. Arlt SP, Haimerl P (2016) Cystic ovaries and ovarian neoplasia in the female dog-a systematic review. Reprod Domest Anim 51(1): 3-11.

6. Banco B, Antuofermo E, Borzacchiello G, Cossu Rocca P, Grieco V (2011) Canine ovarian tumors: an immunohistochemical study with HBME-1 antibody. J Vet diagnostic Investig 23(5): 977-981.

7. Akihara Y, Shimoyama Y, Kawasako K, Komine M, Hirayama K, et al. (2007) Immunohistochemical evaluation of canine ovarian tumors. J Vet Med Sci 69(7): 703-708.

8. Riccardi E, Greco V, Verganti S, Finazzi M (2007) Immunohistochemical diagnosis of canine ovarian epithelial and granulosa cell tumors. J Vet diagnostic Investig 19(4): 431-435.

9. Cathro HP, Stoler MH (2002) Expression of cytokeratins 7 and 20 in ovarian neoplasia. Am J Clin Pathol 117(6): 944-951.

10. Iaria C, Ieni A, Corti I, Puleio R, Brachelente C, et al. (2019) Immunohistochemical study of four fish tumors. J Aquat Anim Health 31(1): 97-106.

11. Lauriano ER, Faggio C, Capillo G, N Spano, M Kuciel, et al. (2018) Immunohistochemical characterization of epidermal dendritic-like cells in giant mudskipper, Periophthalmodon schlosseri. Fish Shellfish Immunol 74: 380-385.

12. Lanteri G, Abbate JM, Iaria C, Macrì D, Ferrantelli V, et al. (2019) Acornrelated acquired pseudomelanosis in Calabrian black pigs. BMC Vet Res 15(1): 186.

13. Lanteri G, Marino F, Liotta L, Stefano C, Macrì B (2011) Experimentally induced melanin-like pigmentation (thesaurismosis) related to acorn ingestion in Nero Siciliano pigs. Acta Vet Hung 59(3): 311-318.

14. Lanteri G, Marino F, Mazzullo G, Macrì B (2010) Cutaneous melanoma and related melanosis of regional lymph nodes in Nero Siciliano pigs. Large Anim Rev 16(6): 285-288.

15. Lanteri G, Marino F, Laganà G (2009) Acquired melanosis caused by acorn ingestion in the Nero Siciliano pig. Vet Pathol 46(2): 329-333.

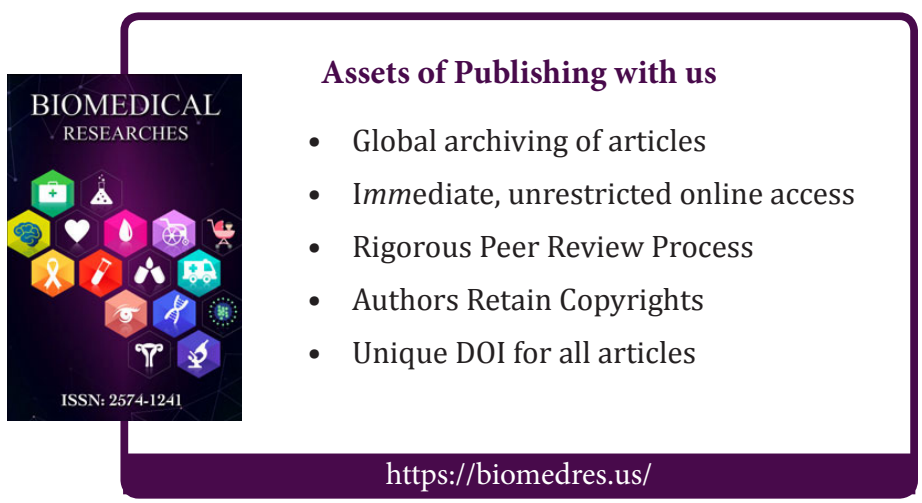

